\title{
Hot punching of high-aspect-ratio 3D polymeric microstructures for drug delivery
}

\author{
Petersen, Ritika Singh; Keller, Stephan Sylvest; Boisen, Anja
}

Published in:

Lab on a Chip

Link to article, DOI:

$10.1039 / \mathrm{c} 5 \mathrm{Ic} 00372 \mathrm{e}$

Publication date:

2015

Document Version

Peer reviewed version

Link back to DTU Orbit

Citation (APA):

Petersen, R. S., Keller, S. S., \& Boisen, A. (2015). Hot punching of high-aspect-ratio 3D polymeric microstructures for drug delivery. Lab on a Chip, 15(12), 2576-2579. https://doi.org/10.1039/c5lc00372e

\section{General rights}

Copyright and moral rights for the publications made accessible in the public portal are retained by the authors and/or other copyright owners and it is a condition of accessing publications that users recognise and abide by the legal requirements associated with these rights.

- Users may download and print one copy of any publication from the public portal for the purpose of private study or research.

- You may not further distribute the material or use it for any profit-making activity or commercial gain

- You may freely distribute the URL identifying the publication in the public portal

If you believe that this document breaches copyright please contact us providing details, and we will remove access to the work immediately and investigate your claim. 


\title{
Hot punching of high-aspect-ratio 3D polymeric microstructures for drug delivery
}

\author{
Ritika S. Petersen ${ }^{\mathrm{a}}$, Stephan S. Keller ${ }^{\mathrm{a}}$, and Anja Boisen ${ }^{\mathrm{a}}$
}

Received ooth January 2012,

Accepted ooth January 2012

DOI: $10.1039 /$ xoxxooooox

www.rsc.org/

Hot punching with two different strategies has been demonstrated as a new method of fabricating high aspect ratio 3D microstructures for drug delivery. It has been shown that this process is highly versatile with good replication fidelity and yield.

Oral drug delivery is the most preferable route of drug delivery. This is due to the ease of administration, flexibility in dosage and most importantly, patient compliance. ${ }^{1}$ However, there are challenges with this route of delivery. These are non-specificity of the drug, degradation in the acidic environment of the stomach and low drug stability resulting in an overall low bioavailability of active ingredients. ${ }^{2,3}$ With the recent developments in Microelectromechanical systems (MEMS) technology, there has been high impetus in developing new microfabricated oral drug delivery systems (DDS) like micropatches, microreservoirs and micropore based devices. ${ }^{4,5}$ For example, Desai et al. have shown in the past years, that microfabricated containers are an oral DDS that can potentially increase the bioavailability of the loaded drug. ${ }^{6,7}$ The first of these microfabricated DDS were produced in conventional materials such as $\mathrm{Si}$, poly(methyl methacrylate) (PMMA) and photoresists. $^{8-10}$ In the last years, there have been efforts to fabricate such oral drug delivery microdevices in biocompatible and biodegradable polymers like poly-l-lactic acid (PLLA), polycaprolactone (PCL), poly(lactic-co-glycolic acid) (PLGA) approved by the US Food and Drug Administration (FDA) for applications in oral drug delivery. ${ }^{11,12}$ In order to fabricate discrete microstructures in such polymers, various fabrication techniques have been developed. DeSimone et al. introduced the PRINT technique which uses molding in a polymer stamp to produce microscale and sub-microscale structures. ${ }^{13,14}$ Guan et al. describe a process to produce foldable hydrogels for drug delivery applications. ${ }^{15}$

Hot embossing is a suitable technique for the fabrication of microstructures in polymers since it is a simple, low cost and scalable process with high structural replication fidelity. However, the residual layer that remains after the hot embossing process poses a challenge to produce discrete microstructures. Some methods to overcome this limitation and remove the residual layer have been introduced in the past including reactive ion etching or laser machining but these processes might affect the material properties of the biopolymer. ${ }^{16,17}$ Kuduva-Raman-Thanumoorthy et al. describe a punching process after hot embossing to get discrete threedimensional (3D) structures using a special set-up. ${ }^{18}$ Heckele et al. introduced bilayer embossing with a device layer on a sacrificial layer. However, this process requires precise control of the penetration depth of the stamp in the sacrificial layer and careful selection of the device and sacrificial layers in order to avoid delamination. ${ }^{19}$

In this paper, we introduce hot punching as a modified hot embossing process to obtain individual biopolymer microcontainers for oral drug delivery applications. These microcontainers are 3D structures with a bottom and high aspect ratio walls forming a reservoir with a volume in the nanoliter range. The overall concept of hot punching is illustrated in Figure 1. The process starts with the deposition of a PLLA device layer on an elastic polydimethylsiloxane (PDMS) layer (Figure 1A1 and B1). After that, the device layer is molded by a robust $\mathrm{Ni}$ stamp and at the same time punched due to the presence of the underlying elastic layer (Figure 1A2 and B2). Once the punching process is finished the microcontainers are separated from the rest of the PLLA film. Depending on the surface pretreatment of PDMS before deposition of the PLLA layer, these microstructures either remain on the underlying PDMS layer (Process A, Figure 1A3 and A4) or are transferred to a sacrificial layer such as a water soluble poly acrylic acid (PAA) layer by thermal bonding (Process B, Figure 1B3 to B7). The hot punching process has several major benefits for fabrication of discrete microstructures: i) The residual layer is penetrated during a single thermal embossing step without formation of residues and without need of additional equipment compared to similar attempts using reactive ion etching or laser machining techniques; ii) The process is very versatile where the PDMS layer can be kept constant while the device material layer can 


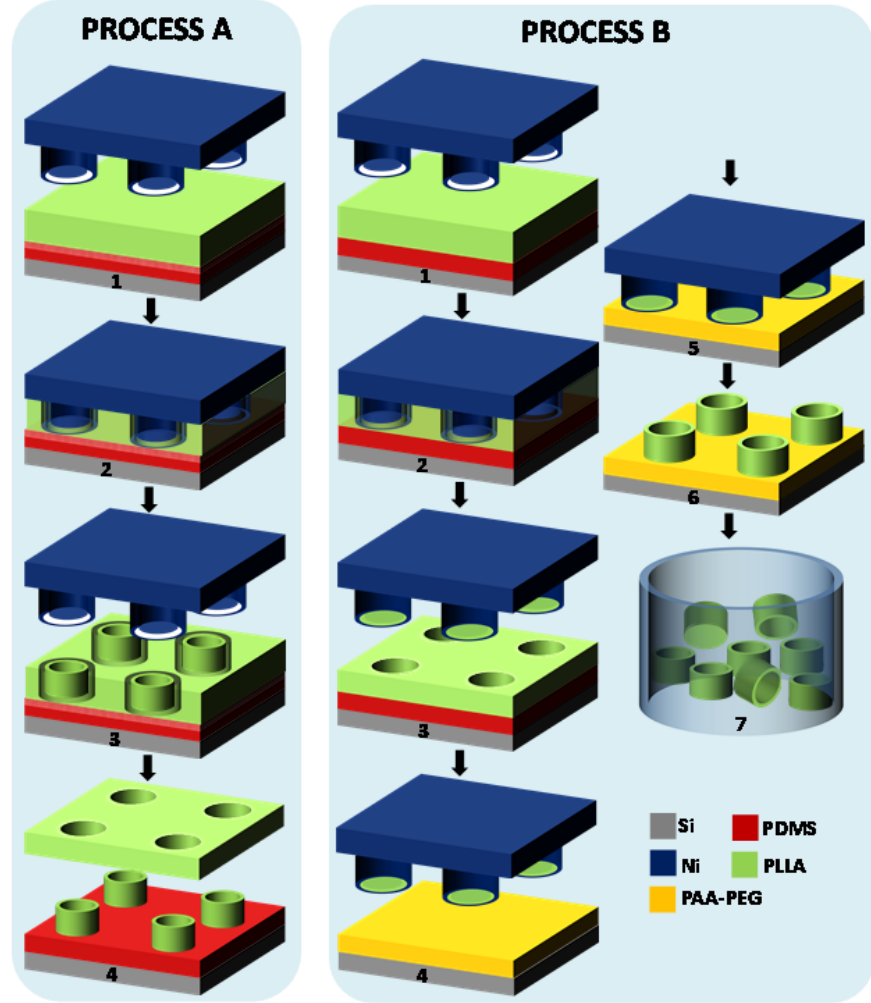

Figure 1 Process A-Hot punching process to fabricate microcontainers on PDMS: A1. Spin coated PLLA film on ozone treated hydrophilic PDMS layer; A2. Hot embossing leading to punching of PLLA containers from the surrounding film; A3. Demolding of the stamp leaving the punched microcontainers on the PDMS layer along with the surrounding polymer film; A4. Hydrophobic recovery of PDMS layer, PLLA containers ready to be collected after peeling of interconnecting film. Process B-Hot punching process to fabricate microcontainers on a PAA-PEG sacrificial layer: B1. Spin coated PLLA film on untreated PDMS layer; B2. Hot embossing leading to punching of PLLA containers from the surrounding film; B3. Demolding of the stamp leaving the microcontainers attached to the Ni stamp; B4. Spin coating of PAA-PEG solution on $\mathrm{Si}$ substrate; B5. Thermal bonding of containers in Ni stamp to sacrificial PAA-PEG layer; B6. Individual microcontainers transferred on PAA-PEG layer after bonding; B7. Released microcontainers floating in water.

be varied to be any thermoplastic polymer; iii) The microcontainers are obtained in ordered arrays solely defined by the stamp design and with the open side of the reservoir pointing upwards which facilitates their handling and further processing such as drug loading by inkjet printing ${ }^{20}$ and functional layer deposition; iv) The process allows fabrication of large high aspect ratio microstructures on wafer-scale. Here, we demonstrate the fabrication of individual high aspect ratio biopolymer microcontainers with heights of $120 \mu \mathrm{m}$ and a volume in the nanoliter range with good replication fidelity and yield.

First, a Ni stamp is fabricated with arrays of stamp units each consisting of an inner disk and an outer ring for fabrication of one individual microcontainer. ${ }^{21}$ The inner disk and the outer ring have a height of $90 \mu \mathrm{m}$ and $120 \mu \mathrm{m}$, respectively. In order to ease the demolding process and successfully replicate the microstructures, the $\mathrm{Ni}$ stamp (Figure 2A) for embossing should have smooth, positively tapered sidewalls. Once the stamp is fabricated, first a $80 \mu \mathrm{m}$ thick PDMS layer and then a $100 \mu \mathrm{m}$ thick PLLA layer are spin coated on a Si substrate.

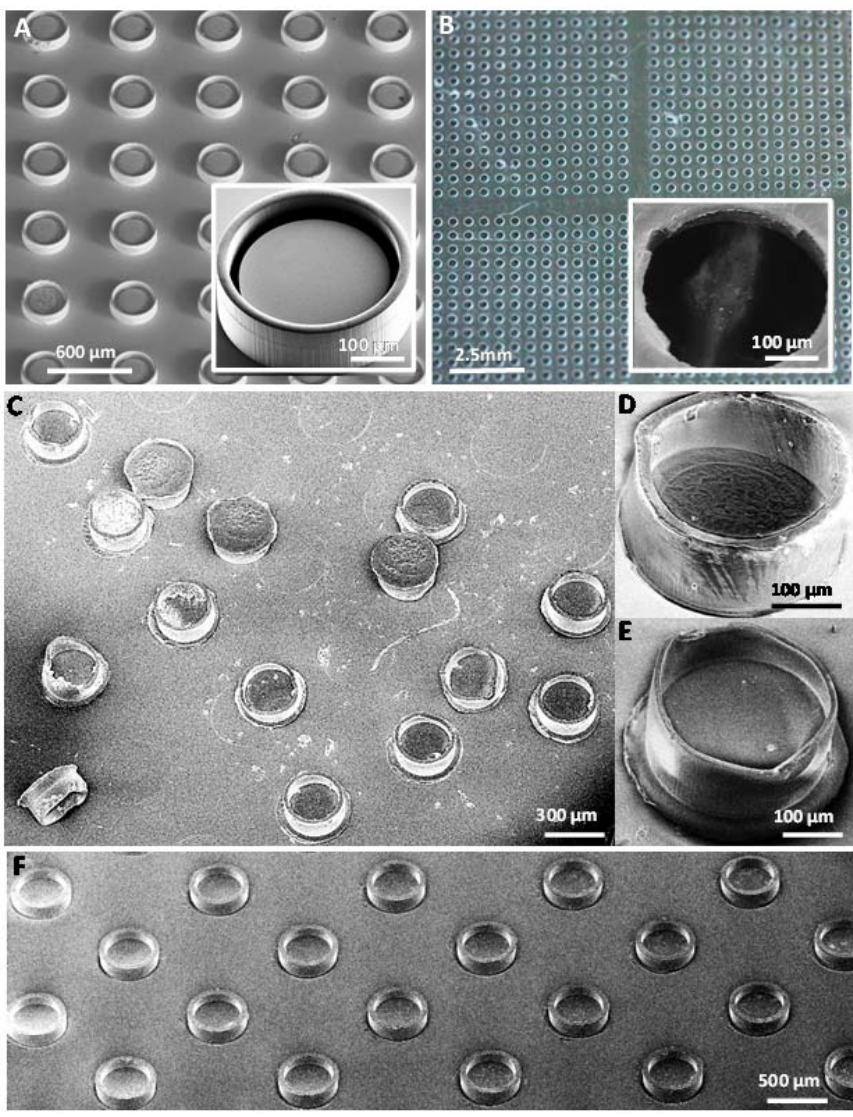

Figure 2 A. SEM micrograph of the Ni stamp, inset: one Ni stamp unit with inner disc of diameter $260 \mu \mathrm{m}, 20 \mu \mathrm{m}$ distance between outer ring and the inner disk and outer ring width of $20 \mu \mathrm{m}$; B. $100 \%$ yield of hot punching; the surrounding polymer film with through holes (inset) after demolding and peeling; C. Loosely attached microcontainers on the PDMS layer after two weeks of storage: D.-E. Individual microcontainers with $20 \mu \mathrm{m}$ (D) and $10 \mu \mathrm{m}$ (E) wall thicknesses; F. PCL microcontainers on PDMS layer immediately after peeling of interconnecting PCL film after hot punching.

Since the maximum height of the structures on the Ni stamp is around $120 \mu \mathrm{m},{ }^{21}$ this thickness of PLLA film ensures that the Ni stamp reaches the PDMS layer during the hot punching process while at the same time it is completely filled by PLLA. The thickness of the PDMS is chosen large enough to ensure that the Ni stamp is far from being in contact with the hard $\mathrm{Si}$ surface beneath it.

The PLLA-PDMS layers stack is brought into contact with the $\mathrm{Ni}$ stamp and embossed at $90{ }^{\circ} \mathrm{C} .{ }^{22}$ During the embossing process, the PLLA polymer is above its glass transition temperature of $55^{\circ}-60^{\circ} \mathrm{C}$ in a viscoelastic state. This viscoelastic layer lies on the elastic PDMS film. When the hard Ni stamp is brought in contact with the viscoelastic PLLA film the PLLA layer starts deforming under the applied compressive forces. This deformation continues into the PDMS layer too. After this, there is only a thin layer of PLLA left below the outer ring of the stamp, which is the highest feature on the stamp. This thin layer defines the residual layer in standard hot embossing. However, because of the elastic deformation of the PDMS layer in the hot punching process, this residual layer is stretched under tensile load. Once the tensile load exceeds the shear strength of the PLLA material, the residual layer is broken. Thus, the containers are separated from the rest of the 
PLLA layer leaving behind holes in the film (Figure 2B). 100\% yield for punching has been achieved in the sample depicted in Figure 2B.

After the embossing process and cooling down to $50{ }^{\circ} \mathrm{C}$, the $\mathrm{Ni}$ stamp is demolded from the polymer stack. Two different strategies (Figure 1, Process A and Process B) can be pursued after demolding based on specific modification of the properties of the PDMS surface before deposition of the PLLA device layer. In process A, the PDMS layer is exposed to UV/Ozone, immediately before spin coating of PLLA. In this case, the punched PLLA film adheres to the PDMS layer. This happens due to the low surface energy $(6 \mathrm{mN} / \mathrm{m})^{23}$ of the $\mathrm{Ni}$ stamp coated with a monolayer of perfluorodecyltrichlorosilane (FDTS) antistiction layer compared to the high surface energy $(72 \mathrm{mN} / \mathrm{m})^{24}$ of the ozone treated PDMS layer.

After punching, the obtained containers are stored for three days during which the PDMS layer recovers some of its hydrophobicity. ${ }^{25}$ After three days it is possible to mechanically peel the interconnecting PLLA film from the PDMS, while the PLLA containers remain attached. After two weeks of storage the containers are only loosely attached to the PDMS as shown in Figure $2 \mathrm{C}$ and can be collected by scraping. Figure $2 \mathrm{E}$ and $\mathrm{F}$ show the microcontainers with $20 \mu \mathrm{m}$ and $10 \mu \mathrm{m}$ wide walls respectively. The walls are close to $120 \mu \mathrm{m}$ high and the reservoir is $90 \mu \mathrm{m}$ deep. It can be observed that high aspect ratios of $>9$ are achieved with this process. Figure $2 \mathrm{~F}$ shows PCL containers attached to the PDMS layer after the interconnecting film has been peeled off. This shows that the process can be extended to other polymers.

In process $\mathrm{B}$, the PDMS layer is not treated with ozone before spin coating of PLLA. In this case, the punched PLLA remains attached to the stamp after demolding. The microcontainers are left in the stamp while the rest of the interconnected PLLA film with the holes is peeled off (Figure 3A). In order to finally obtain the microcontainers, the $\mathrm{Ni}$ stamp with the microcontainers is thermally bonded to a sacrificial layer. Since acrylics are heavily used in adhesives and are water soluble, poly acrylic acid (PAA) is used. In order to enhance the adhesive properties of PAA and to decrease its $T_{g}$, polyethylene glycol (PEG) is added to aqueous solution of PAA. The stamp, with the PLLA containers stuck in it, is bonded to the PAAPEG layer at $60^{\circ} \mathrm{C}$. Once the stamp is removed from the PAAPEG layer, PLLA containers are obtained on this water soluble layer (Figure 3B). As in process A, it can be seen in Figure 3C and $\mathrm{D}$ that high aspect ratio containers can be fabricated using process B. Since the fluorocarbon coating on the Ni stamp lowers its surface energy while PEG addition to PAA increases the surface energy of the sacrificial layer, PLLA has a higher tendency to adhere to the PAA-PEG layer. If required, the microcontainers can be separated from the $\mathrm{Si}$ substrate by dissolution of the PAA-PEG layer in water and further, filtering of microcontainers (Figure 3E).

Process A and B have different advantages and drawbacks. On one hand, when the microcontainers are directly obtained on a PDMS film as in process A, the number of steps is lower than when the microcontainers are transferred on a sacrificial layer as in process B. On the other hand, microcontainers in process $\mathrm{B}$ remain attached to the handling substrate for a longer time. This implies that after process A, the microcontainers can only be stored for a few days during which the drug loading of the
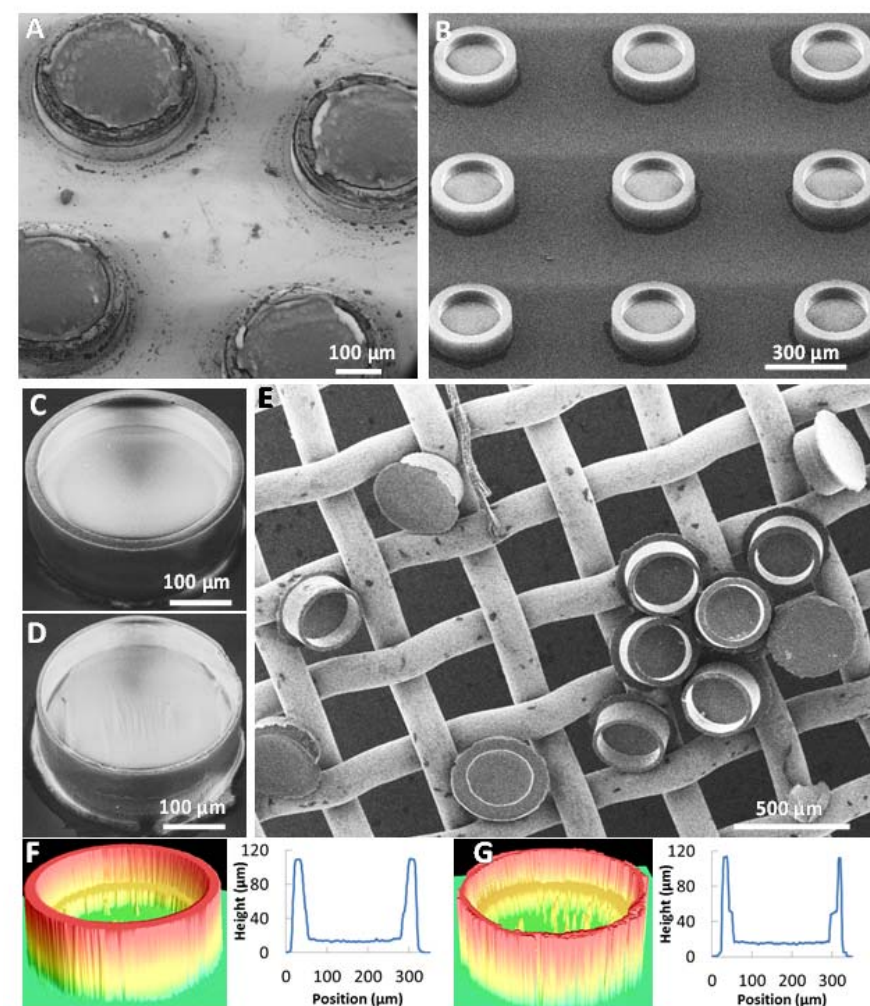

Figure 3 A. Punched microcontainers attached to $\mathrm{Ni}$ stamp after demolding, B. Microcontainers with $40 \mu \mathrm{m}$ wall thicknesses bonded to the PAA-PEG sacrificial layer; C.-D. Individual microcontainers with $20 \mu \mathrm{m}$ (C) and $10 \mu \mathrm{m}$ (D) wall thicknesses; E. Microcontainers filtered through a mesh after dissolution of PAA-PEG sacrificial layer; F. Height profile and 3D image of the microcontainers with $20 \mu \mathrm{m}$ thick walls, G. Height profile and 3D image of the microcontainers with 10 $\mu \mathrm{m}$ thick walls. High aspect ratio of $>9$ and wall heights of $120 \mu \mathrm{m}$ are achieved.

containers needs to be performed before the PDMS layer recovers its hydrophobicity and the containers detach. Process $A$ is a dry process which means that once the containers will be loaded with drug, they will not be exposed to any kind of solvents. Compared to that, process B becomes a wet process due to the release of the containers from the substrate by dissolution of a sacrificial layer. Thus, the choice of process will depend on the final application and the requirements for post-processing such as drug loading.

\section{Conclusions}

We have fabricated individual microcontainers in biodegradable polymer approved for oral drug delivery applications using hot punching. Hot punching is a modification of the standard embossing technique, where an elastic PDMS layer is deposited between the device PLLA layer and the hard Si substrate. We have shown that this layer allows the penetration of the residual layer and the separation of the microcontainers from the surrounding polymer film on wafer scale. We have illustrated that punched microcontainers can be obtained, either on the underlying PDMS film directly or on a sacrificial layer. Here, the sacrificial layer is a water soluble PAA layer but in principle it could be any layer with good adhesion properties to PLLA e.g. an adhesive tape. Both 
processes have good replication fidelity and give excellent yields even for structures with high aspect ratio of $>9$ and a height of $120 \mu \mathrm{m}$ (Figure 3F and G). The final microstructures are truly 3D microcontainers with $300 \mu \mathrm{m}$ diameter and $90 \mu \mathrm{m}$ deep reservoirs resulting in a volume of approximately $4 \mathrm{~nL}$ per container. This is around three orders of magnitudes more volume for drug loading in comparison to some of the other microreservoir based DDS presented in literature. ${ }^{[6,9,26]}$ In future, these microcontainers will be loaded with drugs and the drug release will be characterized.

Finally, we believe that the hot punching process described here is a truly versatile and simple process which is compatible with standard hot embossing equipment and stamps. The process is not limited to fabrication of microcontainers but can be applied to other drug delivery devices or other applications like tissue engineering where fabrication of individual 3D microstructures in polymer is required. This process is suitable for high throughput production and can potentially be transferred to rollto-roll (R2R) processing.

\section{Acknowledgements}

This research is supported by NAMEC Villum Kann Rasmussen Centre of Excellence (65286). We thank the staff at DTU Danchip for support during use of the cleanroom facilities.

\section{Notes and references}

${ }^{a}$ Department of Micro- and Nanotechnology,

Technical University of Denmark,

Building 345B, Kongens Lyngby

DK-2800, Denmark

Electronic Supplementary Information (ESI) available: Experimental section on materials, device fabrication and characterization. See DOI: $10.1039 / \mathrm{c} 000000 \mathrm{x} /$

1 S. V. Sastry, J. R.. Nyshadham, J. A. Fix, Pharm. Sci. Technol. To., 2000, 3, 138

2 M. Morishita, N. A. Peppas, Drug Discov,. Today. 2006, 11, 905.

3 M. Goldberg, I. Gomez-Orellana, Nat. Rev. Drug Discov., 2003, 2, 289.

4 S. Sant, S. L. Tao, O. Z. Fisher, Q. Xu, N. A. Peppas, A. Khademhosseini, Adv. Drug Deliv. Rev., 2012, 64, 496.

5 C. Chiappini, E. Tasciotti, J. R. Fakhoury, D. Fine, L. Pullan, Y-C Wang, L. Fu, X. Liu, M. Ferrari, Chemphyschem, 2010,11, 1029.

6 S. L. Tao, T. A. Desai, Adv. Mater.,2005, 17, 1625.

7 H. D. Chirra, L. Shao, N. Ciaccio, C. B. Fox, J. M. Wade, A. Ma, T. A. Desai, Adv. Healthc. Mater., 2014, 3, 1648.

8 J. T. Santini, M. J. Cima, R. Langer, Nature, 1999, 397, 335.

9 S. L. Tao, M. W. Lubeley, T. A. Desai, J. Control Release, 2003, 88, 215.

10 S. L. Tao, K. Popat, T. A. Desai, Nat. Protoc., 2007, 1, 3153.

11 Y. Zhang, H. F. Chan, K. W. Leong, Adv. Drug Delivery Rev., 2013, 65, 104.
12 L. Brannon-Peppas, Int. J. Pharm., 1995, 116, 1.

13 J. P. Rolland, B. W. Maynor, L. E. Euliss, A. E. Exner, G. M. Denison, J. M. DeSimone. J. Am. Chem. Soc., 2005, 127, 10096.

14 Y. J. Kelly, J. M. DeSimone, J. Am. Chem. Soc., 2008, 130, 5438.

15 J. Guan, H. He, L. J. Lee, D. J. Hansford, Small, 2007, 3, 412.

16 S. J. Pearton, D. P. Norton, Plasma Process Polym., 2005, 2, 16.

17 J. Y. Sheikh-Ahmad, Machining of polymer composites, Springer, New York, USA 2009.

18 R. Kuduva-Raman-Thanumoorthy, D. Yao, Polym. Eng. Sci., 2009, 49, 1894.

19 M. Heckele, W. K. Schomburg, J. Micromech. Microeng., 2004, 14, R1.

20 P. Marizza, S. S. Keller, A. Müllertz, A. Boisen. J. Control Release, 2014, 173, 1 .

21 R. S. Petersen, S. S. Keller, O. Hansen, A. Boisen, J. Micromech. Microeng., 2015, 25, 055021.

22 R. S. Petersen, R. Mahshid, N. K. Andersen, S. S. Keller, H. N. Hansen, A. Boisen, Microelectron. Eng., 2015, 133, 104.

23 D. Janssen, R. De Palma, S. Verlaak, P. Heremans, W. Dehaen, Thin Solid Films, 2006, 515, 1433.

24 K. Efimenko, W. E. Wallace, J. Genzer, J. Colloid Interface Sci. 2002, 254, 306.

25 Y. Berdichevsky, J. Khandurina, A. Guttman, Y. H. Lo, Sens. Actuators B Chem. 2004, 97, 402.

26 A. Ahmed, C. Bonner, T. A. Desai, J. Control Release 2002, 81, 291. 